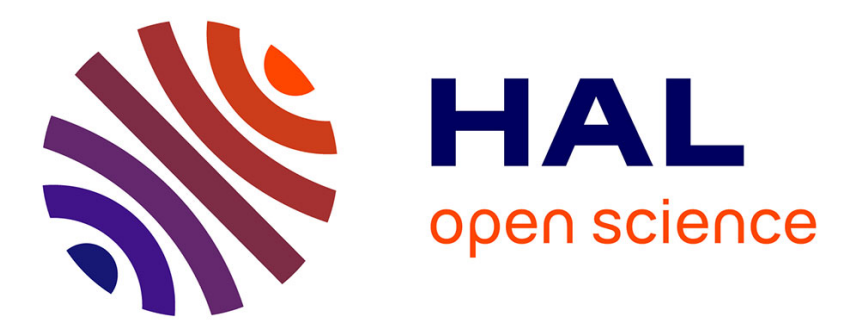

\title{
Gold Nanoparticles on Oxide-Free Silicon-Molecule Interface for Single Electron Transport
}

Louis Caillard, Oliver Seitz, Philip M. Campbell, Rachel P. Doherty, Anne-Félicie Lamic-Humblot, Emmanuelle Lacaze, Yves J. Chabal, Olivier Pluchery

\section{To cite this version:}

Louis Caillard, Oliver Seitz, Philip M. Campbell, Rachel P. Doherty, Anne-Félicie Lamic-Humblot, et al.. Gold Nanoparticles on Oxide-Free Silicon-Molecule Interface for Single Electron Transport. Langmuir, 2013, 29, pp.5066-5073. 10.1021/la304971v · hal-00910966

\section{HAL Id: hal-00910966 https://hal.sorbonne-universite.fr/hal-00910966}

Submitted on 21 Nov 2018

HAL is a multi-disciplinary open access archive for the deposit and dissemination of scientific research documents, whether they are published or not. The documents may come from teaching and research institutions in France or abroad, or from public or private research centers.
L'archive ouverte pluridisciplinaire HAL, est destinée au dépôt et à la diffusion de documents scientifiques de niveau recherche, publiés ou non, émanant des établissements d'enseignement et de recherche français ou étrangers, des laboratoires publics ou privés. 


\title{
Gold Nanoparticles on Oxide-Free Silicon-Molecule Interface for Single Electron Transport
}

\author{
Louis Caillard, ${ }^{\dagger, \ddagger}$ Oliver Seitz, ${ }^{\dagger, \|}$ Philip M. Campbell, ${ }^{\dagger}$ Rachel P. Doherty, ${ }^{\ddagger}$, \\ Anne-Félicie Lamic-Humblot, ${ }^{\S}$ Emmanuelle Lacaze, ${ }^{\dagger}$ Yves J. Chabal, ${ }^{\dagger}$ and Olivier Pluchery* \\ ${ }^{\dagger}$ Laboratory for Surface and Nanostructure Modifications, Department of Materials Science and Engineering, University of Texas at \\ Dallas, 800 West Campbell Road, Dallas, Texas 75080, United States \\ ${ }^{\ddagger}$ Institut des NanoSciences de Paris, Université Pierre et Marie Curie UPMC-CNRS, 4 place Jussieu, 75005 Paris, France \\ ${ }^{\S}$ Laboratoire de Réactivité de Surfaces, Université Pierre et Marie Curie UPMC-CNRS, 3 rue Galilée, 94200 Ivry-sur-Seine, France
}

ABSTRACT: Two different organic monolayers were prepared on silicon $\mathrm{Si}(111)$ and modified for attaching gold nanoparticles. The molecules are covalently bound to silicon and form very ordered monolayers sometimes improperly called self-assembled monolayers (SAM). They are designed to be electrically insulating and to have very few electrical interface states. By positioning the tip of an STM above a nanoparticle, a double barrier tunnel junction (DBTJ) is created, and Coulomb blockade is demonstrated at $40 \mathrm{~K}$. This is the first time Coulomb blockade is observed with an organic monolayer on oxidefree silicon. This work focuses on the fabrication and initial electrical characterization of this double barrier tunnel junction. The organic layers were prepared by thermal hydrosilylation of two different alkene molecules with either a long carbon chain $\left(C_{11}\right)$ or a shorter one $\left(C_{7}\right)$,

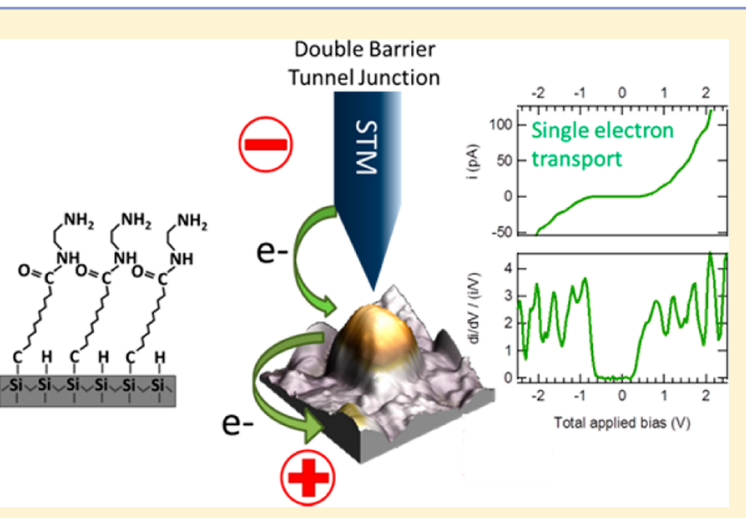
and both were modified to be amine-terminated. FTIR and XPS measurements confirm that the $\operatorname{Si}(111)$ substrate remains unoxidized during the whole chemical process. Colloidal gold nanoparticles were prepared using two methods: either with citrate molecules (Turkevich method) or with ascorbic acid as the surfactant. In both cases AFM and STM images show a wellcontrolled deposition on the grafted organic monolayer. $I-V$ curves obtained by scanning tunneling spectroscopy (STS) are presented on $8 \mathrm{~nm}$ diameter nanoparticles and exhibit the well-known Coulomb staircases at low temperature. The curves are discussed as a function of the organic layer thickness and silicon substrate doping.

\section{INTRODUCTION}

Despite almost 40 years effort and the opening of great routes for future applications, molecular electronics is still in its infancy. Indeed, it offers an unprecedented way for controlling the morphology at the subnanometer level based on its ability to build functional organic layers on silicon substrates as detailed in several recent reviews. ${ }^{1,2}$ A functional organic layer should also be able to carry out electrical functions such as driving charges with a high mobility, storing electrons in a memory device, ${ }^{3}$ or controlling their flow in a transistor. ${ }^{4,5}$ However, this requires a high degree of morphologic organization close to what is achieved in a silicon crystal. If not, the memory will leak and exhibit a poor retention time, the electrons will be trapped, ${ }^{6}$ or the Fermi level will be pinned in a noncontrollable way. ${ }^{7}$ Therefore, it is crucial to succeed in assembling molecules on silicon with atomic precision, starting with the most straightforward layer, an insulating layer.

In this article we describe a chemical route for building two different organic monolayers grafted on silicon and acting as ultrathin insulating layers. In order to probe the electrical quality of the organic layer, gold nanoparticles (AuNP) from colloidal solutions are covalently attached on top of the monolayer. The whole process is achieved by wet chemistry. It preserves an oxide-free silicon substrate that remains stable under ambient conditions. This architecture serves as a first tunnel junction (silicon/organic layer/AuNP junction) and is completed by a second tunnel junction established with an STM tip (AuNP/vacuum/tip junction). Such a double barrier tunnel junction (DBTJ) exhibits an electric behavior characterized by Coulomb blockade which is detectable at $40 \mathrm{~K}$ in UHV. This work focuses on the fabrication and initial electrical characterization of this double barrier tunnel junction.

Coulomb blockade is a typical single charge phenomenon where electrons can be controlled one by one by adjusting the potential applied to the DBTJ. It is based on the fact that the system is mostly capacitive and the value of the capacitance is roughly proportional to the nanoparticle diameter. The electrostatic energy needed to add one more electron to the nanoparticle (called the island) is expressed as $e^{2} / 2 C$, where $e$ is the unit charge and $C$ the capacitance. For very small nanoparticles this energy becomes larger than $k T$ and the electrostatic energy overcomes the thermal noise, so that the 
electron flux can be controlled by an external applied potential. At room temperature, this condition is fulfilled for nanoparticles smaller than $5 \mathrm{~nm}$. In the early 2000s, a strong interest arose for single electron phenomena such as the Coulomb blockade, fueled by the hope of creating new architectures for single charge electronics. ${ }^{8-11}$ Some single electron transistors have been fabricated ${ }^{12-15}$ as well as nonvolatile memories. ${ }^{16,17}$ However, the development of devices based on single electron transport faces serious challenges due to the poor reproducibility of these devices and the difficulty in precisely controlling Coulomb blockade phenomena. One reason for this lies in the insufficient control of the interface quality and the nanogap thickness. ${ }^{18}$ In order to observe single electron phenomena, the targeted device is the DBTJ. Given that the tunnel current depends exponentially on the barrier thickness, an accurate control of the samples geometry is necessary. Moreover, the typical thickness of such junctions lies between 0.8 and $2 \mathrm{~nm}$, which requires that the tunnel barrier thickness must be controlled at the atomic level. Such a control can best be achieved with self-assembled monolayers.

Highly ordered monolayers on silicon have been explored for decades, particularly after the discovery of a process to form atomically flat hydrogen-terminated silicon surfaces in $1989 .{ }^{19}$ Starting from this $\mathrm{H}-\mathrm{Si}(111)-(1 \times 1)$ surface, many chemical routes ${ }^{20}$ have been used for replacing the terminal hydrogen by other molecules: thermal activation ${ }^{21-24}$ UV activation, ${ }^{24-27}$ electrochemical activation, ${ }^{28,29}$ and chlorination. ${ }^{24,30,31}$ More recently, some of these groups started investigating the electrical quality of these organic layers in order to integrate them within future functional architectures. ${ }^{1,32}$ The monolayer is probed either globally, with the mercury drop method, ${ }^{33,34}$ with electrochemistry, ${ }^{27}$ by depositing an oxide layer ${ }^{35}$ or a metallic electrode, or sometimes local probes such as KPFM or conductive AFM are used. ${ }^{26}$ From these studies, it appears that the $\mathrm{Si}$-organics interface can be made with a notably low amount of surface defects, in line with expectations based on the $\mathrm{H}-\mathrm{Si}(111)$ interface. ${ }^{33,35,36}$ Interestingly silicon surfaces functionalized with organics are usually much more stable against oxidation $^{6}$ (e.g., up to 1 month) than $\mathrm{H}-\mathrm{Si}(111)$ surfaces, which is encouraging for implementing a robust functional molecular passivation of silicon surfaces.

\section{EXPERIMENTAL METHODS}

Preparation of Highly Ordered Monolayers on $\mathrm{Si}(111)$. Samples of $5 \times 12 \mathrm{~mm}^{2}$ were cut from n-doped silicon (111) wafers with resistivity of either $0.03 \Omega \cdot \mathrm{cm}\left(\sim 1 \times 10^{18} \mathrm{~cm}^{-3}\right)$ or $7 \Omega \cdot \mathrm{cm}(\sim 6$ $\left.\times 10^{14} \mathrm{~cm}^{-3}\right)$. Float zone (FZ) grown samples were chosen in order to minimize the amount of oxygen and allow an accurate monitoring of potential surface oxidation with FTIR. ${ }^{23,30,37}$ It should be noted that the chemistry described here works equally well with Czochralskigrown wafers but depends on the level of doping. ${ }^{26}$ Functional organic monolayers were prepared within four steps (see Scheme 1). In step 1, samples were initially cleaned in a piranha solution at $80{ }^{\circ} \mathrm{C}(3: 1$ $\mathrm{H}_{2} \mathrm{SO}_{4} 98 \%: \mathrm{H}_{2} \mathrm{O}_{2} 30 \%$ ) and copiously rinsed with ultrapure water (18 Mohm $\cdot \mathrm{cm}$, Millipore). Atomically flat, hydrogen-terminated $\mathrm{Si}(111)-(1 \times 1)$ surfaces were prepared by oxide removal in a concentrated HF solution for $30 \mathrm{~s}$, followed by a $150 \mathrm{~s}$ immersion in $40 \% \mathrm{NH}_{4} \mathrm{~F}$ solution and thorough rinsing in deionized water. ${ }^{19,26,38}$ Caution is recommended because the piranha solution reacts strongly with organics, and the HF solution is extremely harmful. Both solutions should be handled with due protection: goggles and suitable gloves. Starting from a set of two different hydrogen-terminated $\mathrm{Si}(111)-(1 \times 1)$ surfaces, step 2 consists of covalently attaching the organic layer by direct thermal hydrosilylation with either a long alkyl chain of 11 carbon
Scheme 1. The Four Steps for Preparing the Two Kinds of the Grafted Organic Monolayer Considered in This Study

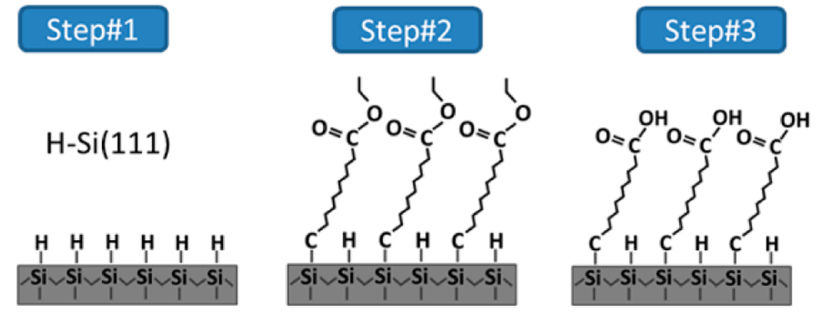

Step\#4

$\mathrm{Si}-\mathrm{C}_{11}$

$\mathrm{Si}_{-} \mathrm{C}_{7}$
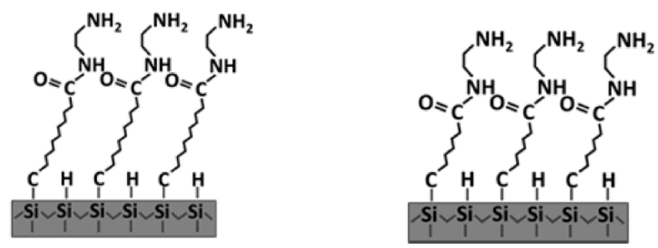

atoms $\left(\mathrm{Si}-\mathrm{C}_{11}\right.$ samples) or a shorter chain with 7 carbon atoms $(\mathrm{Si}-$ $\mathrm{C}_{7}$ samples).

$S i-C_{11}$. 10-Carboxydecyl organic monolayers were grafted on the hydrogenated silicon via direct thermal hydrosilylation of ethyl undecylenate. The neat alkene was outgassed three times by freezing it using liquid nitrogen under low vacuum $\left(10^{-2}\right.$ Torr $)$ in a Schlenk tube. It was then heated up to $200{ }^{\circ} \mathrm{C}$ under continuous argon bubbling when inserting the freshly prepared $\mathrm{H}$-terminated silicon sample. Grafting was performed for $4 \mathrm{~h}$.

$S i-C_{7}$. 6-Carboxydecyl organic monolayers were grafted on the hydrogenated silicon via direct thermal hydrosilylation of ethyl 6heptenoate diluted $(1: 1)$ in mesitylene following the same procedure described above. Notable differences are the use of a lower vacuum during the outgassing step (10 Torr) with liquid $\mathrm{N}_{2}$, and thermal hydrosilylation is performed at $170{ }^{\circ} \mathrm{C}$. Both modifications are done to avoid evaporation of the molecule and most of the solvent during the preparation and the reaction. At the end of this second step both organic monolayers are terminated with a protected carboxylic acid.

In step 3, the functionalized surfaces were sonicated in ethyl acetate and rinsed in boiling dichloromethane $\left(40^{\circ} \mathrm{C}\right)$. The carboxylic acids groups were then deprotected by using potassium tert-butoxide in DMSO (for $90 \mathrm{~s}$ and then rinsed thoroughly with DMSO) and by finally using an acid solution $(\mathrm{HCl})$ to protonate the active group. Finally, step 4 is the transformation of the functional headgroup into succinimidyl ester-terminated. This was performed by reaction with an aqueous solution of $N$-ethyl- $N^{\prime}$-(3-(dimethylamino)propyl)carbodiimide (EDC). After a few minutes in EDC solution, $1 \mathrm{~mL}$ of ethylenediamine is added to the solution for $1 \mathrm{~h} 30 \mathrm{~min}$ at room temperature. Finally, the surface was rinsed with ultrapure water. During the last step, one amine group of the ethylenediamine molecule $\left(\mathrm{H}_{2} \mathrm{~N}-\mathrm{CH}_{2}-\mathrm{CH}_{2}-\mathrm{NH}_{2}\right)$ reacts with the activated ester, leading to the attachment of the molecule via an amide bond $(-(\mathrm{C}=$ $\mathrm{O})-\mathrm{NH}-\mathrm{CH}_{2}-\mathrm{CH}_{2}-\mathrm{NH}_{2}$ ). It is very unlikely that the ethylenediamine binds in a bridging configuration through its two amine ends because the molecule length $(2.99 \AA)$ is shorter than the typical distance between two $\mathrm{COOH}$ groups estimated from the $\mathrm{Si}-\mathrm{Si}$ distance. Therefore, at the end of step 4, the resulting surface presents amine groups on top of the layer. $36,39,40$

FTIR Characterization of the Grafted Organic Monolayers. All FTIR spectra were taken using a Nicolet 6700 FTIR spectrometer from Thermo Scientific equipped with a DTGS detector in transmission mode at an angle of incidence of $64^{\circ}$ with respect to the $\mathrm{Si}$ surface normal in a dry $N_{2}(\mathrm{~g})$-purged atmosphere and with an unpolarized IR beam. The spectra were obtained after the initial 
molecular attachment and deprotection of the carboxylic acid, i.e., after step 3. The reference spectra were recorded in both cases using the oxide-free, fully hydrogen-terminated $\mathrm{Si}(111)$ surfaces.

In the case of $\mathrm{Si}-\mathrm{C}_{11}$, no oxide was detected. This surface remains robust against oxidation as evidenced by the absence of any detectable absorption at 1080 and $1240 \mathrm{~cm}^{-1}$ ( $\mathrm{TO}$ and $\mathrm{LO}$ modes of $\mathrm{SiO}_{2}$ oxide) in Figure 1. In the case of $\mathrm{Si}-\mathrm{C}_{7}$ a negligible amount of oxide shows

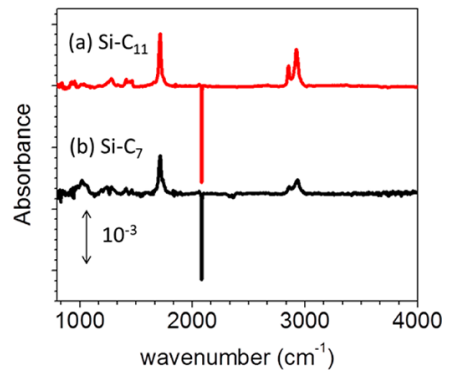

Figure 1. FTIR transmission spectra showing the organic monolayer fabrication when the surface is terminated with carboxylic acid at step 3 (see Scheme 1). The monolayer was obtained by thermal hydrosilylation with ethyl undecylenate (abbreviated $\mathrm{Si}-\mathrm{C}_{11}$, spectrum a) and ethyl 6-heptenoate $\left(\mathrm{Si}-\mathrm{C}_{7}\right.$, spectrum $\left.\mathrm{b}\right)$. The reference spectra were recorded in both cases using the oxide-free, fully hydrogenated $\operatorname{Si}(111)-(1 \times 1)$ surface. These spectra demonstrate that the hydrosilylation process occurs without oxidizing the silicon substrate.

up at $1080 \mathrm{~cm}^{-1}$. This oxide uptake is due to the time spent by the sample in air, needed for recording the FTIR spectra, and this characterization step was discarded for the samples used for STM measures. The negative peak at $2093 \mathrm{~cm}^{-1}$ is due to the replacement of $\mathrm{Si}-\mathrm{H}$ bonds with $\mathrm{Si}-\mathrm{C}$ bonds in the hydrosilylation process. Knowing that a fully hydrogen-terminated $\mathrm{Si}$ surface exhibits a $\mathrm{Si}-\mathrm{H}$ line with an area of $0.08 \mathrm{~cm}^{-1}$, an area comparison between the $\mathrm{Si}-\mathrm{H}$ peak before and after molecular grafting shows that a coverage of roughly $1 / 2$ of the surface is obtained for the $\mathrm{SiC}_{11}$ and slightly more for the $\mathrm{SiC}_{7}$. Half of the hydrogen atoms remains on the unreacted silicon atoms as depicted in Scheme 1. The peak at $1713 \mathrm{~cm}^{-1}$ is assigned to the terminal $\mathrm{C}=\mathrm{O}$ bond. The two peaks at 1280 and $1410 \mathrm{~cm}^{-1}$ correspond to the $\mathrm{C}-\mathrm{O}$ bonds, and the $1461 \mathrm{~cm}^{-1}$ band is due to the bending mode of the methylene groups of the alkyl chains. The positive peaks in the range of 2880 and $2920 \mathrm{~cm}^{-1}$ are due to the $\mathrm{CH}_{2}$ chains. They exhibit a higher area in the case of $\mathrm{Si}-\mathrm{C}_{11}$, confirming the presence of a longer chain.

XPS Characterization of the Grafted Organic Monolayer. Surface analysis after molecular grafting using X-ray photoelectron spectroscopy after step 2 confirms that there is no oxide present (see Figure 2) and gave almost identical results for both monolayers: in the vicinity of $\mathrm{Si} 2 \mathrm{p}$ core level shift, there is no evidence of $\mathrm{Si}$ oxidation (i.e., at $103.2 \mathrm{eV}$ ). Moreover, the $\mathrm{C} 1 \mathrm{~s}$ region shows the specific peaks corresponding to the ester $(290.0 \mathrm{eV})$, the $\mathrm{C}-\mathrm{O}$ bond $(288.0 \mathrm{eV})$, the $\mathrm{C}-\mathrm{C}$ bond $(285.0 \mathrm{eV})$, and the $\mathrm{Si}-\mathrm{C}$ bond $(284.5 \mathrm{eV})$. This last peak is less intense than the $\mathrm{C}-\mathrm{O}$ and the ester peaks because it corresponds to carbon located deeper in the sample; i.e., fewer photoelectrons can escape. An additional peak is also observed at 286 $\mathrm{eV}$ and is attributed to organic contamination because of exposure to air after surface chemistry during transport to the XPS chamber.

Spectroscopic ellipsometry measurements were also performed on the samples before gold nanoparticle deposition using an HORIBA Jobin Yvon ellipsometer (iHR320). After organic modification, the thickness and the dielectric constant of each organic layer are determined using a simple two-layer model similarly to our previous study. ${ }^{23}$ The thicknesses of the layers derived from the results are 1.6 $\mathrm{nm}$ for the $\mathrm{Si}-\mathrm{C}_{11}$ and $1.3 \mathrm{~nm}$ for the $\mathrm{Si}-\mathrm{C}_{7}$. These results are in agreement with the expected values (1.67 and $1.28 \mathrm{~nm}$, respectively) calculated from the geometry of the molecules.

After monolayer preparation and initial characterization, the samples were express shipped inside an argon-filled plastic container
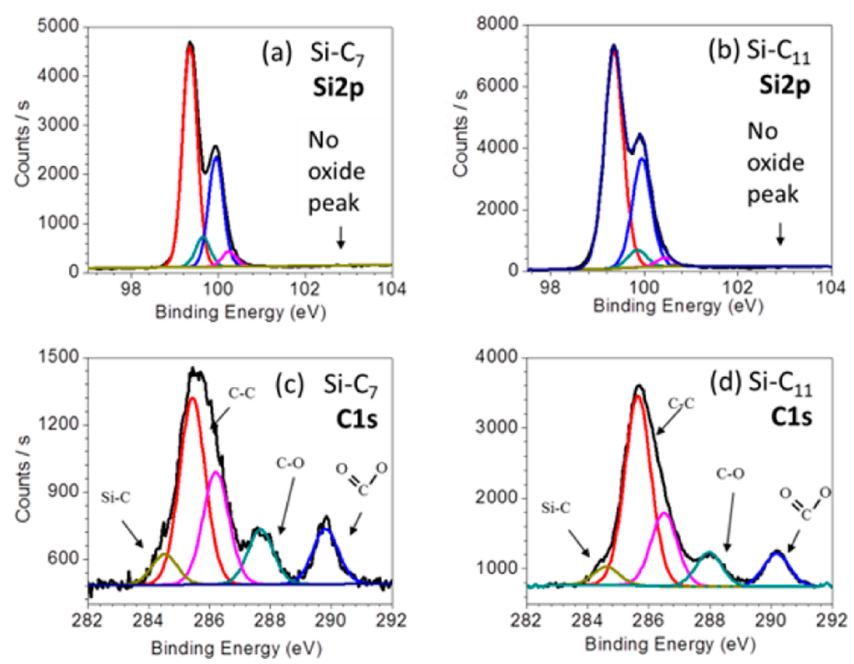

Figure 2. XPS characterization of $\mathrm{Si}-\mathrm{C}_{11}$ and $\mathrm{Si}-\mathrm{C}_{7}$ molecules after thermal hydrosilylation. The C 1s peaks between 284.5 and $290.0 \mathrm{eV}$ observed for both $\mathrm{Si}-\mathrm{C}_{7}$ (a) and $\mathrm{Si}-\mathrm{C}_{11}$ (b) confirm that the molecules are grafted on the surface. The $\mathrm{Si} 2 \mathrm{p}$ regions for $\mathrm{Si}-\mathrm{C}_{7}(\mathrm{c})$ and $\mathrm{Si}-\mathrm{C}_{11}(\mathrm{~d})$ contain no evidence of oxidation.

from Dallas to Paris. The samples were stored under vacuum at a pressure of $10^{-8}$ Torr as soon as they were received. The surfaces were subsequently further functionalized by gold nanoparticles and then characterized with UHV STM. It is important to stress that the samples remain stable in air for several days, before notable oxidation of the $\mathrm{Si}-\mathrm{C}_{11}$ surface is observed. We checked that STM was able to image straightforwardly the surface as long as it is not kept in air for too long a time. Typically after 2 weeks in air, STM imaging is no longer possible because silicon oxide has regrown underneath the organic layers with a thicknesses greater than ca. $0.6 \mathrm{~nm}$, an oxide thickness preventing proper STM under normal conditions. ${ }^{41}$ This stability against silicon oxidation of these grafted organic monolayers is one of their main interests.

Gold Nanoparticle Preparation and Deposition. Two different methods were used to prepare colloidal gold nanoparticles (AuNP):

1. Turkevich AuNP. The citrate reduction method for synthesizing gold nanoparticles in water was pioneered by Turkevich et al. in $1951^{42}$ and modified by Frens in 1973 . $^{43}$ It remains one of the most popular methods for producing spherical monodisperse gold nanoparticles. An aqueous solution of $\mathrm{HAuCl}_{4}(20 \mathrm{~mL}, 0.25 \mathrm{mM})$ was boiled under refluxing conditions and vigorous stirring. Sodium citrate was quickly added $(1 \mathrm{~mL}, 18 \mathrm{mM})$, and the solution color changed from faintly yellowish to clear gray, purple, and finally dark purple within 2-3 min. The resulting AuNP have a diameter of typically 15 $\mathrm{nm}$ as already established ${ }^{44-46}$ and demonstrated below by AFM. In this reaction, citrate first acts as a reducing agent and tends to adsorb onto the metallic gold clusters, slowing down their growth and resulting in size regulation. Moreover, citrate ions are negatively charged such that the nanoparticles repel each other. ${ }^{45,47,48}$

2. Ascorbic Acid Nanoparticles (asc-AuNP). The asc-AuNP were synthesized following a method described elsewhere. ${ }^{49}$ Typically, 200 $\mu \mathrm{L}$ of an aqueous solution of $\mathrm{HAuCl}_{4} \cdot 3 \mathrm{H}_{2} \mathrm{O}\left(10 \mathrm{~g} \mathrm{~L}^{-1}\right.$ of gold $)$ was added to $25 \mathrm{~mL}$ of water at around $2{ }^{\circ} \mathrm{C}$ (ice-cooled) in a beaker. Then, $1.5 \mathrm{~mL}$ of a $\mathrm{Na}_{2} \mathrm{CO}_{3}$ solution $\left(21.2 \mathrm{~g} \mathrm{~L}^{-1}\right)$ and $1 \mathrm{~mL}$ of an ascorbic acid solution $\left(7 \mathrm{~g} \mathrm{~L}^{-1}\right)$ were added under vigorous stirring. The solution became instantaneously dark red.

Deposition of AuNP on the organic monolayer was performed by dipping the functionalized silicon substrate into the colloidal solutions. The attachment occurs through the interaction between the $-\mathrm{NH}_{2}$ moiety of the organic layer and gold surface. In the case of Turkevich AuNP the maximum nanoparticle coverage is reached after $1 \mathrm{~h}$ and occurs with an initial step of electrostatic attraction between the negatively charged citrate and the $-\mathrm{NH}_{3}{ }^{+}$end group which is protonated due to the acidity of the Turkevich solution $(\mathrm{pH}=5)$. In 
the case of the asc-AuNP, the solution was first acidified to $\mathrm{pH}=6$ with a $0.1 \mathrm{M}$ hydrochloric acid solution. The solution color remained unchanged. The functionalized silicon surface was dipped into the AuNP solutions for $12 \mathrm{~min}$, allowing the particles to become grafted onto the amino-terminated surface while remaining well separated. In both cases, the substrate was cleaned after the dipping by several rinses in deionized water and dried with a nitrogen gas stream.

AFM Characterization of AuNP on the Monolayer. AFM was performed on these surfaces using the tapping mode with a Digital Instrument DI-3000 (Figure 3a) or a Multimode-8 instrument from Veeco (Figure $3 b$ ) and were processed with the software WSxM. ${ }^{50}$
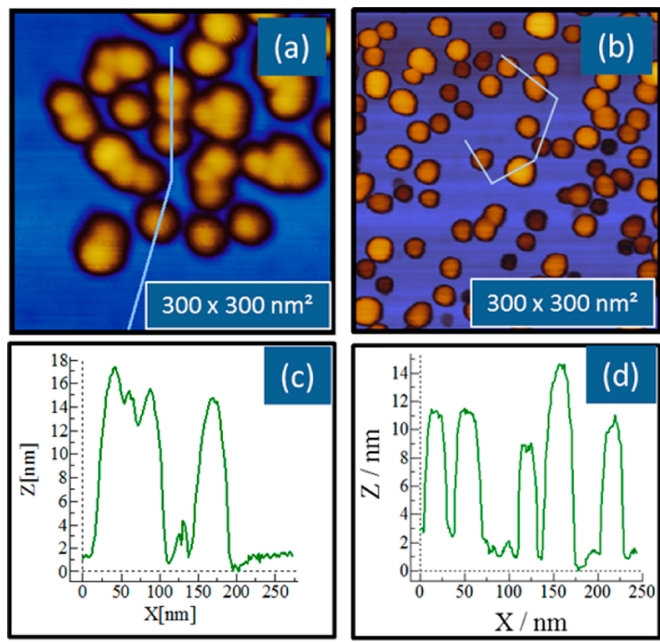

Figure 3. AFM images in tapping mode of AuNP deposited on highly ordered monolayers on $\mathrm{Si}(111)-(1 \times 1)$ surfaces. The Turkevich nanoparticles $\left(\mathrm{a}, \mathrm{c}\right.$ ) were deposited on the $\mathrm{Si}-\mathrm{C}_{11}$ organic layer and the asc-AuNP $(b, d)$ on a $\mathrm{Si}-\mathrm{C}_{7}$ organic layer.

In the case of the Turkevich AuNP, the deposition was carried out as a test experiment to make sure that attachment occurred on the oxide-free monolayer investigated here similarly to what had been previously demonstrated in other publications dealing with monolayer on oxidized silanized silicon surfaces. ${ }^{44,46,51}$ The amino-terminated monolayer layer was confirmed as being very efficient at immobilizing the nanoparticles, ${ }^{23}$ and the AFM images acquired in tapping mode showed no indication that the AuNP were moved by the tip. However, Turkevich nanoparticles are too large (diameter $\sim 15 \mathrm{~nm}$ ) to exhibit Coulomb blockade at room temperature since this phenomenon requires NPs diameter around $5 \mathrm{~nm}$. Therefore, we concentrate on the asc-AuNP. As shown in Figure 3b, the asc-AuNP are randomly distributed over the organic layer and there was no aggregation. Based on their profile height, the average size of the nanoparticles is $9.5 \mathrm{~nm}$ (standard deviation of $2.5 \mathrm{~nm}$ ). Practically, this means that it is possible to find nanoparticles with a diameter between 4 and $15 \mathrm{~nm}$ on a typical AFM or STM image. The roughness of the underlying substrate without nanoparticles was measured to be $0.36 \mathrm{~nm}$.

STM. STM images were recorded with a commercial apparatus (Omicron VT-STM) whose UHV chamber has a base pressure of $4 \times$ $10^{-11}$ Torr, in which the sample could be cooled down to $25 \mathrm{~K}$ with a coldfinger in contact with liquid helium. The samples were introduced into the preparation chamber with a load-lock and then annealed at $150{ }^{\circ} \mathrm{C}$ for $30 \mathrm{~min}$ before STM imaging. This annealing procedure removes any physisorbed water molecules and greatly improves the image quality by minimizing fuzzy structures during imaging. The organic layer is not affected by this thermal treatment because it was prepared at similar temperatures. Imaging a given sample before and after annealing (though not on the same area) allowed verification that the AuNP distribution did not change significantly before and after this annealing procedure. In the STM experiments, the indicated voltage is the bias of the surface relative to the tip.

\section{RESULTS AND DISCUSSION}

STM Characterization. STM images of the two kinds of organic-functionalized surfaces (see Scheme 1) were recorded in UHV at room temperature prior to AuNP deposition, as shown in Figures $4 a$ and $4 b$. The surfaces are remarkably flat

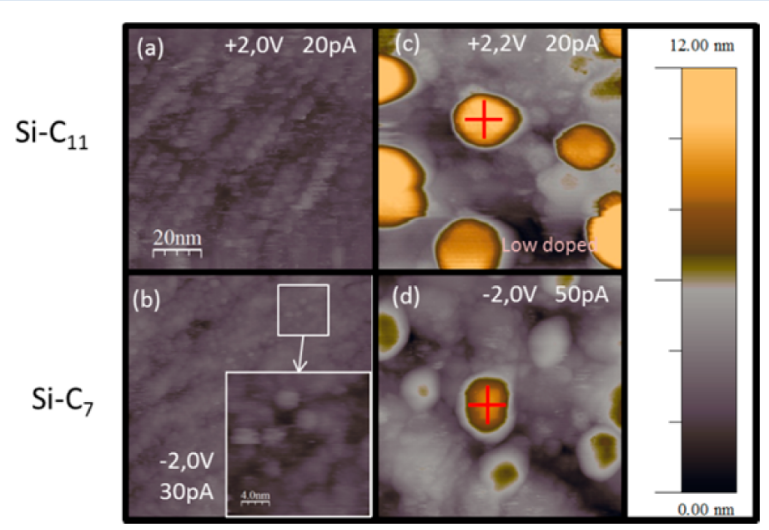

Figure 4. STM images $\left(100 \times 100 \mathrm{~nm}^{2}\right)$ of different surfaces of organic layers grafted with a $\mathrm{Si}-\mathrm{C}$ bond to the $\mathrm{Si}(111)$ substrate. Surfaces (a) and (c) were prepared with the long chain molecule ( $\mathrm{Si}-$ $\mathrm{C}_{11}$ ) and surfaces $(\mathrm{b})$ and $(\mathrm{d})$ with the shorter chain $\left(\mathrm{Si}-\mathrm{C}_{7}\right)$. Inset in image (b) is a $20 \times 20 \mathrm{~nm}^{2}$ zoom of the surface with an enhanced contrast showing the molecular bundles on the surface. On both surfaces, asc-AuNP have been grafted through the $-\mathrm{NH}_{2}$ terminal group of the organic monolayer (images $c$ and $d$ ). The cross indicates the AuNP where STS was performed. Images (a) and (b) have been recorded at room temperature and images (c) and (d) at low temperatures ( 25 and $37 \mathrm{~K}$, respectively). Scanning conditions are given on the images (gap voltage and current set point).

with a rms roughness of 0.33 and $0.38 \mathrm{~nm}$, respectively, in agreement with AFM experiments, which indicates that the monolayer is very well ordered. The surface shown in Figure 4a exhibits parallel lines that are attributed to the silicon terraces. ${ }^{26}$ The inset in Figure $4 \mathrm{~b}$ shows that $3 \mathrm{~nm}$ large protrusions can be resolved, corresponding to bundles of $\sim 10$ molecules. ${ }^{52}$ STM imaging found no notable differences between $\mathrm{Si}-\mathrm{C}_{7}$ and $\mathrm{Si}-$ $\mathrm{C}_{11}$ surfaces.

After the asc-AuNP were grafted ex situ as described above, the samples were analyzed again by STM. As evidenced in Figures $4 \mathrm{c}$ and $4 \mathrm{~d}$, AuNP are clearly visible, with a topographic distribution comparable to what was measured by AFM (Figure 3 ). The AuNP were strongly attached and could not been displaced by the STM tip as might occur on other systems such as self-assembled monolayer on $\mathrm{Au}(111)$. The diameters of two particles (marked with a cross in Figures $4 \mathrm{c}$ and $4 \mathrm{~d}$ ) were evaluated, taking advantage of their height and found to be 7.5 $\mathrm{nm}$ for both particles.

STS Measurement. After acquiring an STM image, the current-voltage spectra $I(V)$ were recorded on various AuNP selected on the basis of their size (closest to $5 \mathrm{~nm}$ ) and having sufficient separation from neighboring particles. The tip was placed above each AuNP at a distance determined by the current set point used for imaging, typically between 20 and 50 pA. At ca. $40 \mathrm{~K}$, the typical lateral drift was $0.4 \mathrm{~nm} / \mathrm{min}$ after 1 $\mathrm{h}$ stabilization time. For each image and before $I(V)$ acquisition, this drift was precisely calculated, and a correction was applied so that the tip did not move more than $0.01 \mathrm{~nm}$ over a nanoparticle during data acquisition. After having switched off the feedback loop, a series of 40 spectra were acquired and 
averaged. However, a few curves were usually dropped from the averages because of tip mechanical instability. As depicted in Scheme 2, positioning the STM tip over a gold nanoparticle

Scheme 2. Configuration Used To Build a Double Barrier Tunnel Junction with the Tip of the STM Placed above a Nanoparticle

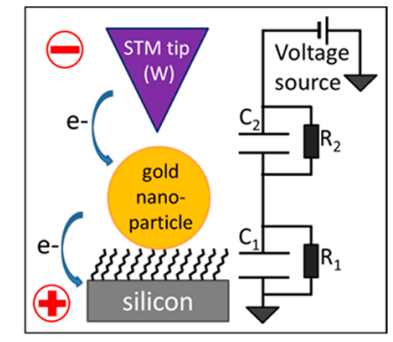

creates a double barrier tunnel junction (DBTJ). The first barrier is composed of the organic layer and the second of the vacuum gap between the tip and the nanoparticle. This system can be electrically modeled by the circuit represented in Scheme 2 where each tunnel junction is represented by a capacitance and a resistance in parallel. If the two junctions are symmetric, the $I=f(V)$ curve exhibits a Coulomb blockade region $(-e / 2 C<V<e / 2 C)$ where no current flows through the DBTJ, and an Ohmic behavior is expected outside this region. On the other hand, if the DBTJ is asymmetric, the $I=f(V)$ curve is staircase-like, and the number of extra electrons simultaneously present in the island is a discrete number directly controlled by $V .{ }^{53}$ About 100 AuNP were investigated under different conditions: three different temperature ranges (room temperature, $100 \mathrm{~K}$ with liquid nitrogen, and 25-40 K with liquid helium cooling), two different monolayer thicknesses $\left(\mathrm{C}_{7}\right.$ and $\left.\mathrm{C}_{11}\right)$, two different substrate doping, and several AuNP diameters ranging from 4 to $10 \mathrm{~nm}$. In this paper, we select a few examples to illustrate the performance of this organic monolayer-based system, and we restrict ourselves to nanoparticles of one size.

Coulomb Blockade. $I(V)$ spectra on three AuNP of similar size $(8 \mathrm{~nm})$ are presented in Figure 5: two spectra were recorded with the same $\mathrm{Si}-\mathrm{C}_{11}$ monolayer, but with two different substrate doping levels, and the third spectrum was taken on the thinner $\mathrm{Si}-\mathrm{C}_{7}$ layer. They illustrate the understanding of the influence of the thickness of the tunnel barrier and the influence of the semiconductor doping level on electron transport. The spectra were recorded at low temperatures $(25,37$, and $100 \mathrm{~K}$, respectively). In all three samples, Coulomb staircases were observed (top graph of Figure 5) and are evidenced by differentiating the $i(V)$ spectrum and calculating $(\mathrm{d} i / \mathrm{d} V) /(i / V)$. The quantity $\mathrm{d} i / \mathrm{d} V$ is proportional to the local density of states (LDOS) and allows detecting the electrostatic energy levels generated by Coulomb blockade in the metallic island. ${ }^{11}$ Each Coulomb oscillation in the differentiated curve corresponds to a step of the Coulomb staircase, indicative of an additional electron stored in the nanoparticle. These results demonstrate that the quality of an organic monolayer on silicon can be such that they act as a local tunnel barrier between the substrate and a metallic nanoparticle and that it is possible to prevent an insulating oxide from being spontaneously formed. However, the exact Coulomb blockade behavior depends on many parameters such as the size and shape of nanoparticles, their crystallinity, ${ }^{54}$ the presence of an
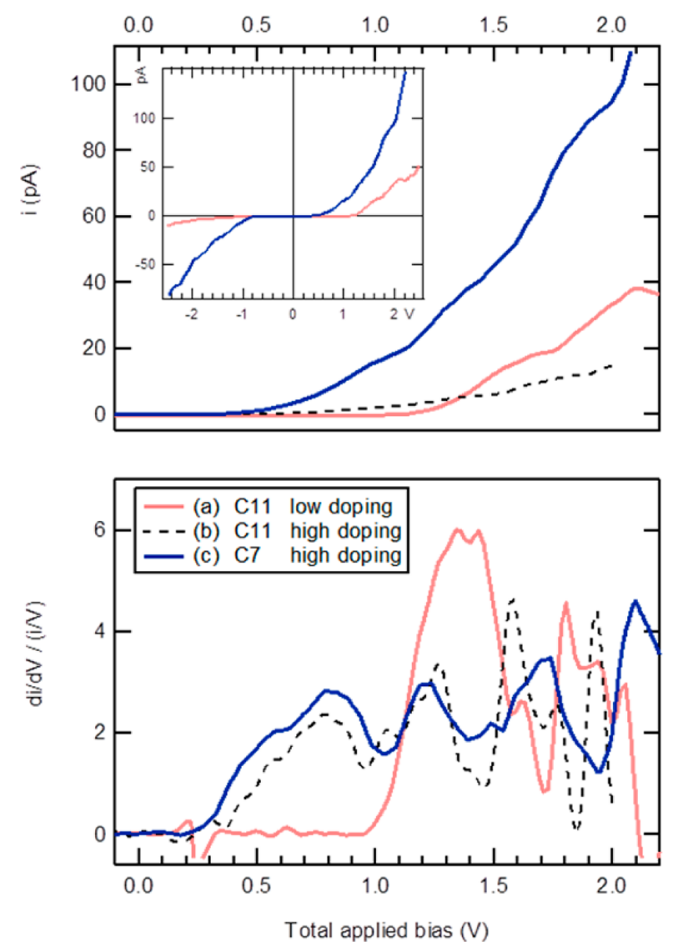

Figure 5. Tunnel spectroscopy on $8 \mathrm{~nm}$ nanoparticles at low temperatures $(25,100$, and $37 \mathrm{~K}$, respectively) showing Coulomb staircases (upper graph) and its derivative $(\mathrm{d} i / \mathrm{d} V) /(i / V)$ (lower graph). Each peak of the derivative corresponds to a supplemental electron added to the nanoparticles. Spectra (a) and (c) were recorded on the AuNP marked with a cross in Figures $4 c$ and $4 d$, respectively. The silicon substrates were $\mathrm{n}$-doped in all cases with a carrier density of $4 \times 10^{14} \mathrm{~cm}^{-3}, 7 \times 10^{17} \mathrm{~cm}^{-3}$, and $2 \times 10^{18} \mathrm{~cm}^{-3}$, respectively.

organic surfactant on the nanoparticle, and the actual bonding between the nanoparticle and the organic layer. These delicate issues have barely been investigated in the literature so far, and we do not address them in detail in the present article. A further analysis of our acquired data set will be reported in a forthcoming article and will focus on the transport measurements in a more quantitative approach. Nevertheless, we checked that on the three nanoparticles discussed herein Coulomb blockade was repeatedly observed during a measurement campaign and that for a given particle the positions of the $\mathrm{d} i / \mathrm{d} V$ peaks were reproduced within an interval of $0.08 \mathrm{~V}$.

In the case of the low doped substrate $\left(N_{\mathrm{d}}=6 \times 10^{14} \mathrm{~cm}^{-3}\right)$ and with the $\mathrm{Si}-\mathrm{C}_{11}$ layer (curve a in Figure 5), the current onset is measured at $V_{0}=1.37 \mathrm{~V}$, and the second step shows up at $V_{1}=1.87 \mathrm{~V}$ (see Table 1 for an overview of the relevant experimental values). According to the theory developed for Coulomb phenomena on metals, ${ }^{10,53}$ the step position is given by $V_{n}=(2 n+1) e^{2} / 2 C$ : the current onset is expected at a potential that is the half of the step width. Obviously this is not the case in the present experiments since $V_{0} \neq 1 / 2\left(V_{1}-V_{0}\right)$. In order to understand the reason for this apparent discrepancy, the doping of the substrate was increased to $N_{\mathrm{d}}=7 \times 10^{17}$ $\mathrm{cm}^{-3}$, keeping the same molecular insulating layer and the same nanoparticle diameter. In this case the current onset was lowered to $V_{0}=0.85 \mathrm{~V}$, and the first step is measured at $V_{1}=$ $1.22 \mathrm{~V}$ (curve $\mathrm{b}$ in Figure 5). The difference between the measured and theoretical onset is due to the strong band bending effect occurring in silicon substrates and particularly in those that are low doped. These effects are qualitatively shown 
Table 1. Electric Characteristics of the Coulomb Staircases Measured with Our Silicon Substrates ${ }^{a}$

\begin{tabular}{|c|c|c|c|c|c|c|c|c|c|c|c|}
\hline Figure & $\underset{\mathrm{cm}^{-3}}{\text { doping/ }}$ & $\begin{array}{c}\text { organic } \\
\text { layer }\end{array}$ & $\begin{array}{l}\text { temp } \\
(\mathrm{K})\end{array}$ & $\begin{array}{l}\text { NP diam } \\
(\mathrm{nm})\end{array}$ & $\begin{array}{c}V_{0} \text { onset } \\
\text { (V) }\end{array}$ & $\begin{array}{c}V_{1} \text { 2nd step } \\
(\mathrm{V})\end{array}$ & $\begin{array}{l}V_{2} \text { third } \\
\text { step }\end{array}$ & $\begin{array}{c}V_{3} \text { 2nd step } \\
\text { (V) }\end{array}$ & $\begin{array}{l}\Delta V \text { Step width } \\
(\mathrm{mV})\end{array}$ & $\underset{(\mathrm{pA})}{\Delta i \text { step height }}$ & tunnel conditions \\
\hline $5 a$ & $\stackrel{\text { low }}{6 \times 10^{14}}$ & $\mathrm{Si}-\mathrm{C}_{11}$ & 25 & 8.2 & 1.37 & 1.87 & 2.39 & & 500 & 20 & $20 \mathrm{pA},+2.2 \mathrm{~V}$ \\
\hline $5 b$ & $\begin{array}{l}\text { high } \\
7 \times 10^{17}\end{array}$ & $\mathrm{Si}-\mathrm{C}_{11}$ & 100 & 8.0 & 0.85 & 1.22 & 1.58 & 1.92 & 370 & 2 & $5 \mathrm{pA},+2.0 \mathrm{~V}$ \\
\hline $5 c$ & $\stackrel{\text { high }}{2 \times 10^{18}}$ & $\mathrm{Si}-\mathrm{C}_{7}$ & 37 & 7.5 & 0.80 & 1.20 & 1.65 & 2.10 & 420 & 15 & $50 \mathrm{pA},-2.0 \mathrm{~V}$ \\
\hline
\end{tabular}

${ }^{a}$ The voltages are obtained with an accuracy of $0.05 \mathrm{~V}$.

Scheme 3. Energy Diagram of the DBTJ ${ }^{a}$

(a) No bias applied

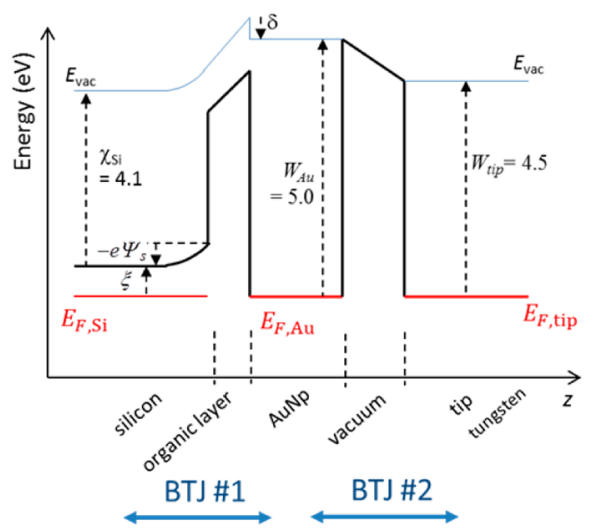

(b) Positive bias applied (depletion)

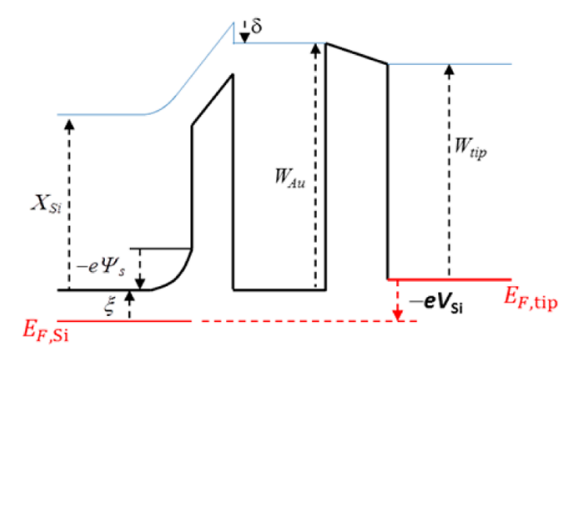

${ }^{a_{T}}$ The first barrier tunnel junction is between the silicon and the selected AuNP, and the second BTJ is between this AuNP and the STM tip.

in Scheme 3 where the energy profile is drawn as a function of the distance away from the silicon surface. This scheme clearly shows the two barriers that an electron needs to cross in order to travel from the substrate to the STM tip. In the present case, both barriers are of the order of $1 \mathrm{~nm}$ and an electron can tunnel through them. The profile is derived from the work functions of all the materials of the DBTJ, knowing that the Fermi levels should be aligned through the entire structure when no bias is applied. ${ }^{55,56}$ For the first barrier tunnel junction (denoted BTJ \#1), the work function of silicon $W_{\mathrm{Si}}$ is given by the sum of the electron affinity of silicon $\chi_{\mathrm{Si}}$ and the energy difference $\xi=E_{\mathrm{C}}-E_{\mathrm{F}, \mathrm{Si}}$ such that $W_{\mathrm{Si}}=\chi_{\mathrm{Si}}+\xi \approx 4.4 \mathrm{eV} \cdot \chi_{\mathrm{Si}}$ is slightly attenuated by the electrostatic dipole generated by the molecular layer. The molecular dipole $\delta$ is independent of the applied bias and was evaluated at around $-0.4 \mathrm{~V}$ in similar cases. $^{22,57}$ In Scheme 3 this dipole shows up as shift of the vacuum level indicative of an electric field close to the organic surface. The Fermi levels of silicon and gold are aligned at equilibrium, and since the work function of gold is $W_{\mathrm{Au}}=5.0$ $\mathrm{eV}$, it results in the creation of an electric field between the two materials so that the bands of the semiconductor tend to bend upward even at zero applied bias. As a consequence of this band bending, an interface potential is generated, denoted $\Psi_{S}$ in Scheme 3 . When a positive bias $V_{\mathrm{Si}}$ is applied as depicted in case $b$ of Scheme 3 , the band bending is amplified and the electron needs to roll up this supplemental hill to reach the tip. As a result, a supplemental amount of energy needs to be provided, which is done by further increasing the applied voltage $V_{\mathrm{Si}}$. This effect is all the more important when the doping is low. This explains why the steps of the Coulomb staircases were detected at higher potential for the low doped samples. Therefore, band bending has two consequences: first, the actual interface potential applied to the silicon/organic
layer/AuNP system is much weaker than the external potential applied by the STM tip, and the electrons need to climb this supplemental barrier. Second, the process depends on the thickness of this barrier, which can be very thin in the case of high doping allowing the charges to tunnel through it. This is not the case for low doped substrates due to band bending. The band bending potential at zero bias has been evaluated to be $+0.60 \mathrm{~V}$ for low n-doped substrate $\left(10^{15} \mathrm{~cm}^{-3}\right)$ and $+0.50 \mathrm{~V}$ for highly n-doped silicon $\left(10^{19} \mathrm{~cm}^{-3}\right)$ by Cahen's group. ${ }^{58}$ Hacker found a value of $+0.26 \mathrm{~V}$ with low $n$-doped substrate $\left(4 \times 10^{14}\right.$ $\left.\mathrm{cm}^{-3}\right) .^{22}$ Although these two values differ, probably because of the different ways of estimating the molecular interface dipole, they confirm the order of magnitude of the voltage shift observed in our experiments.

Finally, with the shorter $\mathrm{Si}-\mathrm{C}_{7}$ monolayer, the Coulomb phenomena are even more pronounced, as shown in curve $\mathrm{c}$ of Figure 5: the steps are clearly visible, and the current is stronger due to a higher conductance of this thinner organic layer. The current onset is detected at $0.80 \mathrm{~V}$, very similar to curve $b$, because the doping level and nanoparticle diameters are identical. The step widths are also comparable. It is not possible to compare the step height since the tunneling conditions were not the same for these three experiments (see last column of Table 1), and the actual tip-nanoparticle distances differ and are unknown in all three cases.

The inset in Figure 5 illustrates another consequence of working with a low doped substrate. With the high doped substrate, the $i(V)$ is almost symmetric with stairs in positive and reverse bias. At positive and reverse biases, the current onset is measured at +0.80 and $-0.89 \mathrm{~V}$, respectively. However, for a low doped substrate, no current is detected in reverse bias, and the junction behaves like a Schottky diode. 


\section{CONCLUSION}

For the first time, a self-assembled monolayer made with organic molecules covalently grafted on oxide-free silicon has been used for measuring Coulomb blockade. This grafted organic monolayer consists of a highly ordered 10-carboxydecyl organic monolayer on silicon which is further modified with an amine termination designed for covalently attaching colloidal gold nanoparticles. By using the tip of an UHV-STM system, above a gold nanoparticle, a double barrier tunnel junction was formed and was found to exhibit clear Coulomb staircase, as evident in the $I-V$ plots. The influence of the doping level of the silicon substrates on the electrical behavior of this system has been investigated. Low doped substrates induce a strong band bending near the $\mathrm{Si} /$ organic layer/Au junction, so such that the actual interface potential is much lower than the applied bias. The step width of the Coulomb staircases is therefore increased, compared to the case of highly doped silicon. Finally, the hydrosilylation method for preparing the organic layer was successfully applied for attaching shorter molecules, and we also investigated the influence of monolayer thickness on the step heights. Results suggest that the step heights are found to be higher for the thinner monolayer as expected. These results open a way for using such grafted organic monolayers on oxide-free silicon as active layers for molecular electronics.

\section{AUTHOR INFORMATION}

\section{Corresponding Author}

*E-mail olivier.pluchery@insp.jussieu.fr.

\section{Present Address}

"O.S.: Rolith, Inc., 5880 W. Las Positas Blvd, Pleasanton, CA 94588.

\section{Notes}

The authors declare no competing financial interest.

\section{ACKNOWLEDGMENTS}

R.D. acknowledges a financial support from Labex-Matisse program from UPMC. The work carried out at UTD (wet chemical modification and spectroscopic characterization) was supported by the National Science Foundation (Grant CHE0911197) and partly by the Texas Higher Education Coordinating Board (NHAR Program). P.M.C. has taken part of the project through Eugene McDermott Scholars Program. Some aspects of the work described herein has benefited from the help and fruitful discussions with several colleagues to whom we want to express our sincere gratitude: Philippe Dollfus, Souhir Boujday, Irina Ionica, and Ahmed Naitabdi.

\section{REFERENCES}

(1) Vilan, A.; Yaffe, O.; Biller, A.; Salomon, A.; Kahn, A.; Cahen, D. Molecules on Si: electronics with chemistry. Adv. Mater. 2010, 22 (2), 140-159.

(2) Vuillaume, D. Molecular nanoelectronics. Proc. IEEE 2011, 98 (12), 2111-2123.

(3) Vuillaume, D.; Lenfant, S. The metal/organic monolayer interface in molecular electronic devices. Microelectron. Eng. 2003, 70, 539-550.

(4) Clement, N.; Pleutin, S.; Guerin, D.; Vuillaume, D. Relaxation dynamics in covalently bonded organic monolayers on silicon. Phys. Rev. B 2010, 82 (3), 035404.

(5) Dubey, G.; Rosei, F.; Lopinski, G. P. Modulation of flat-band voltage on $\mathrm{H}$-terminated silicon-on-insulator pseudo-metal-oxidesemiconductor field effect transistors by adsorption and reaction events. J. Appl. Phys. 2011, 109 (10), 104904.
(6) Aureau, D.; Rappich, J.; Moraillon, A.; Allongue, P.; Ozanam, F.; Chazalviel, J.-N. In situ monitoring of the electronic properties and the $\mathrm{pH}$ stability of grafted $\mathrm{Si}(111)$. J. Electroanal. Chem. 2010, 646 (1-2), $33-42$.

(7) Lenfant, S.; Guerin, D.; Van, F. T.; Chevrot, C.; Palacin, S.; Bourgoin, J. P.; Bouloussa, O.; Rondelez, F.; Vuillaume, D. Electron transport through rectifying self-assembled monolayer diodes on silicon: Fermi-level pinning at the molecule-metal interface. J. Phys. Chem. B 2006, 110 (28), 13947-13958.

(8) Asahi, N.; Akazawa, M.; Amemiya, Y. Single-electron logic device based on the binary decision diagram. IEEE Trans. Electron Devices 1997, 44 (7), 1109-1116.

(9) Davidovic, D.; Tinkham, M. Coulomb blockade and discrete energy levels in Au nanoparticles. Appl. Phys. Lett. 1998, 73 (26), 3959.

(10) Likharev, K. K. Single-electron devices and their applications. Proc. IEEE 1999, 87 (4), 606-632.

(11) Zabet-Khosousi, A.; Dhirani, A. A. Charge transport in nanoparticle assemblies. Chem. Rev. 2008, 108 (10), 4072-4124.

(12) Yang, Y.; Nogami, M. Room temperature single electron transistor with two-dimensional array of $\mathrm{Au}-\mathrm{SiO}_{2}$ core-shell nanoparticles. Sci. Technol. Adv. Mater. 2005, 6 (1), 71-75.

(13) Ray, V.; Subramanian, R.; Bhadrachalam, P.; Liang-Chieh, M.; Kim, C.-U.; Koh, S. J. CMOS-compatible fabrication of room temperature single-electron devices. Nat. Nanotechnol. 2008, 3, 603608.

(14) Khondaker, S. I.; Luo, K.; Yao, Z. The fabrication of singleelectron transistors using dielectrophoretic trapping of individual gold nanoparticles. Nanotechnology 2010, 21 (9), 095204.

(15) Tsai, L.-C.; Cheng, I.-C.; Tu, M.-C.; Chen, C.-D.; Lin, H.-Y. Formation of single-electron-transistors using self-assembly of nanoparticle chains. J. Nanopart. Res. 2010, 12 (8), 2859-2864.

(16) Novembre, C.; Guerin, D.; Lmimouni, K.; Gamrat, C.; Vuillaume, D. Gold nanoparticle-pentacene memory transistors. Appl. Phys. Lett. 2008, 92 (10), 103314.

(17) Chan, K. C.; Lee, P. F.; Dai, J. Y. Mesoscopic phenomena in Au nanocrystal floating gate memory structure. Appl. Phys. Lett. 2009, 95 (11), 113109-3.

(18) Homberger, M.; Simon, U. On the application potential of gold nanoparticles in nanoelectronics and biomedicine. Philos. Trans. $R$. Soc., A 2010, 368 (1915), 1405-1453.

(19) Higashi, G. S.; Chabal, Y. J.; Trucks, G. W.; Raghavachari, K. Ideal hydrogen termination of the $\mathrm{Si}(111)$ surface. Appl. Phys. Lett. 1990, 56 (7), 656-8.

(20) Tao, F.; Bernasek, S. L.; Xu, G. Q. Electronic and structural factors in modification and functionalization of clean and passivated semiconductor surfaces with aromatic systems. Chem. Rev. 2009, 109 (9), 3991-4024.

(21) Linford, M. R.; Fenter, P.; Eisenberger, P. M.; Chidsey, C. E. D. Alkyl monolayers on silicon prepared from 1-alkenes and hydrogenterminated silicon. J. Am. Chem. Soc. 1995, 117, 3145-3155.

(22) Hacker, C. A. Modifying electronic properties at the siliconmolecule interface using atomic tethers. Solid-State Electron. 2010, 54 (12), 1657-1664

(23) Aureau, D.; Varin, Y.; Roodenko, K.; Seitz, O.; Pluchery, O.; Chabal, Y. J. Controlled deposition of gold nanoparticles on welldefined organic monolayer grafted on silicon. J. Phys. Chem. C 2010, 114 (33), 14180-14186.

(24) Li, Y.; Calder, S.; Yaffe, O.; Cahen, D.; Haick, H.; Kronik, L.; Zuilhof, $\mathrm{H}$. Hybrids of organic molecules and flat, oxide-free silicon: high-density monolayers, electronic properties, and functionalization. Langmuir 2012, 28 (26), 9920-9929.

(25) Voicu, R.; Boukherroub, R.; Bartzoka, V.; Ward, T.; Woityk, J. T. C.; Wayner, D. D. M. Formation, characterization, and chemistry of undecanoic acid-terminated silicon surfaces: patterning and immobilization of DNA. Langmuir 2004, 20 (26), 11713-11720.

(26) Miramond, C.; Vuillaume, D. 1-Octadecene monolayers on $\mathrm{Si}(111)$ hydrogen-terminated surfaces: Effect of substrate doping. J. Appl. Phys. 2004, 96 (3), 1529-1536. 
(27) Faucheux, A.; Gouget-Laemmel, A. C.; Henry deVilleneuve, C.; Boukherroub, R.; Ozanam, F.; Allongue, P.; Chazalviel, J. N. Welldefined carboxyl-terminated alkyl monolayers grafted onto $\mathrm{H}-\mathrm{Si}(111)$ : Packing density from a combined AFM and quantitative IR study. Langmuir 2006, 22 (1), 153-162.

(28) Fellah, S.; Teyssot, A.; Ozanam, F.; Chazalviel, J.-N.; Vigneron, J.; Etcheberry, A. Kinetics of electrochemical derivatization of the silicon surface by Grignards. Langmuir 2002, 18 (15), 5851-5860.

(29) Teyssot, A.; Fidelis, A.; Fellah, S.; Ozanam, F.; Chazalviel, J. N. Anodic grafting of organic groups on the silicon surface. Electrochim. Acta 2002, 47 (16), 2565-2571.

(30) Webb, L. J.; Rivillon, S.; Michalak, D. J.; Chabal, Y. J.; Lewis, N. S. Transmission infrared spectroscopy of methyl- and ethyl-terminated silicon(111) surfaces. J. Phys. Chem. B 2006, 110 (14), 7349-7356.

(31) Puniredd, S. R.; Assad, O.; Stelzner, T.; Christiansen, S.; Haick, $H$. Catalyst-free functionalization for versatile modification of nonoxidized silicon structures. Langmuir 2011, 27 (8), 4764-4771.

(32) Salomon, A.; Boecking, T.; Chan, C. K.; Amy, F.; Girshevitz, O.; Cahen, D.; Kahn, A. How do electronic carriers cross Si-bound alkyl monolayers? Phys. Rev. Lett. 2005, 95 (26), 266807.

(33) Seitz, O.; Boecking, T.; Salomon, A.; Gooding, J. J.; Cahen, D. Importance of monolayer quality for interpreting current transport through organic molecules: Alkyls on oxide-free Si. Langmuir 2006, 22 (16), 6915-6922.

(34) Thieblemont, F.; Seitz, O.; Vilan, A.; Cohen, H.; Salomon, E.; Kahn, A.; Cahen, D. Electronic current transport through molecular monolayers: Comparison between $\mathrm{Hg}$ /alkoxy and alkyl monolayer/ Si(100) junctions. Adv. Mater. 2008, 20 (20), 3931.

(35) Peng, W.; Seitz, O.; Chapman, R. A.; Vogel, E. M.; Chabal, Y. J. Probing the intrinsic electrical properties of thin organic layers/ semiconductor interfaces using an atomic-layer-deposited $\mathrm{Al}_{2} \mathrm{O}_{3}$ protective layer. Appl. Phys. Lett. 2012, 101 (5), 051605-5.

(36) Seitz, O.; Fernandes, P. G.; Mahmud, G. A.; Wen, H.-C.; Stiegler, H. J.; Chapman, R. A.; Vogel, E. M.; Chabal, Y. J. One-step selective chemistry for silicon-on-insulator sensor geometries. Langmuir 2011, 27 (12), 7337-7340.

(37) Ogawa, H.; Ishikawa, K.; Inomata, C.; Fujimura, S. Initial stage of native oxide growth on hydrogen terminated silicon (111) surfaces. J. Appl. Phys. 1996, 79 (1), 472-477.

(38) Allongue, P. Molecular imaging and local density of states characterization at the $\mathrm{Si}(111) / \mathrm{NaOH}$ interface. Phys. Rev. Lett. 1996, 77 (10), 1986-1989.

(39) Seitz, O.; Dai, M.; Aguirre-Tostado, F. S.; Wallace, R. M.; Chabal, Y. J. Copper-metal deposition on self assembled monolayer for making top contacts in molecular electronic devices. J. Am. Chem. Soc. 2009, 131 (50), 18159-18167.

(40) Seitz, O.; Caillard, L.; Nguyen, H. M.; Chiles, C.; Chabal, Y. J.; Malko, A. V. Optimizing non-radiative energy transfer in hybrid colloidal-nanocrystal/silicon structures by controlled nanopillar architectures for future photovoltaic cells. Appl. Phys. Lett. 2012, 100 (2), 021902

(41) Xue, K.; Ho, H. P.; Xu, J. B. Local study of thickness-dependent electronic properties of ultrathin silicon oxide near $\mathrm{SiO}_{2} / \mathrm{Si}$ interface. J. Phys. D: Appl. Phys. 2007, 40 (9), 2886.

(42) Turkevich, J.; Stevenson, P. C.; Hillier, J. Discuss. Faraday Soc. 1951, 11, 55-75.

(43) Frens, G. Controlled nucleation for regulation of particle-size in monodisperse gold suspensions. Nature (London), Phys. Sci. 1973, 241 (105), 20-22.

(44) Diegoli, S.; Mendes, P. M.; Baguley, E. R.; Leigh, S. J.; Iqbal, P.; Diaz, Y. R. G.; Begum, S.; Critchley, K.; Hammonds, G. D.; Evans, S. D.; Attwood, D.; Jones, I. P.; Preece, J. A. pH-dependent gold nanoparticle self-organization on functionalized $\mathrm{Si} / \mathrm{SiO}_{2}$ surfaces. J. Exp. Nanosci. 2006, 1 (3), 333-353.

(45) Kimling, J.; Maier, M.; Okenve, B.; Kotaidis, V.; Ballot, H.; Plech, A. Turkevich method for gold nanoparticle synthesis revisited. J. Phys. Chem. B 2006, 110 (32), 15700-15707.

(46) Pluchery, O.; Lacaze, E.; Simion, M.; Miu, M.; Bragaru, A.; Radoi, A. In Optical Characterization of Supported Gold Nanoparticles for Plasmonic Biosensors; Semiconductor Conference (CAS), 2010 International Sinaia, Romania, 2010; IEEE Electron Devices Society: Sinaia, Romania, 2010; pp 159-162.

(47) Roucoux, A.; Schulz, J.; Patin, H. Reduced transition metal colloids: A novel family of reusable catalysts? Chem. Rev. 2002, 102 (10), 3757-3778.

(48) Ji, X. H.; Song, X. N.; Li, J.; Bai, Y. B.; Yang, W. S.; Peng, X. G. Size control of gold nanocrystals in citrate reduction: The third role of citrate. J. Am. Chem. Soc. 2007, 129, 13939-13948.

(49) Stathis, E. C.; Fabrikanos, A. Preparation of colloidal gold. Chem. Ind. 1958, 27, 860-861.

(50) Horcas, I.; Fernandez, R.; Gomez-Rodriguez, J. M.; Colchero, J.; Gomez-Herrero, J.; Baro, A. M. WSXM: A software for scanning probe microscopy and a tool for nanotechnology. Rev. Sci. Instrum. 2007, 78, 013705.

(51) Lee, S.; Yoon, J. H.; Yoon, S. Adsorption patterns of gold nanoparticles on methyl-terminated self-assembled monolayers. J. Phys. Chem. C 2011, 115 (25), 12501-12507.

(52) de Smet, L. C. P. M.; Pukin, A. V.; Sun, Q.-Y.; Eves, B. J.; Lopinski, G. P.; Visser, G. M.; Zuilhof, H.; Sudhölter, E. J. R. Visiblelight attachment of $\mathrm{SiC}$ linked functionalized organic monolayers on silicon surfaces. Appl. Surf. Sci. 2005, 252 (1), 24-30.

(53) Mullen, K.; Benjacob, E.; Jaklevic, R. C.; Schuss, Z. I-V characteristics of coupled ultrasmall-capacitance normal tunneljunctions. Phys. Rev. B 1988, 37 (1), 98-105.

(54) Lu, W.; Wang, B.; Wang, K. D.; Wang, X. P.; Hou, J. G. Synthesis and characterization of crystalline and amorphous palladium nanoparticles. Langmuir 2003, 19 (14), 5887-5891.

(55) Sze, S. M. Physics of Semiconductor Devices, 2nd ed.; John Wiley \& Sons: New York, 1981; p 868.

(56) Brennan, K. F. The Physics of Semiconductors: With Applications to Optoelectronic Devices; Cambridge University Press: Cambridge, 1999; p 762.

(57) Hunger, R.; Fritsche, R.; Jaeckel, B.; Jaegermann, W.; Webb, L. J.; Lewis, N. S. Chemical and electronic characterization of methylterminated $\mathrm{Si}(111)$ surfaces by high-resolution synchrotron photoelectron spectroscopy. Phys. Rev. B 2005, 72, 045317-045323.

(58) Yaffe, O.; Scheres, L.; Segev, L.; Biller, A.; Ron, I.; Salomon, E.; Giesbers, M.; Kahn, A.; Kronik, L.; Zuilhof, H.; Vilan, A.; Cahen, D. $\mathrm{Hg} /$ molecular monolayer-Si junctions: Electrical interplay between monolayer properties and semiconductor doping density. J. Phys. Chem. C 2010, 114 (22), 10270-10279. 